\title{
Facilitating Referee's Decision Making in Sport via the Application of Technology
}

\author{
René Leveaux \\ School of Systems, Management and Leadership, University of Technology, Sydney, Australia
}

\begin{abstract}
The aim of this study was to examine the current uses of technologies to assist referee decision making processes in professional and Olympic sports, to provide the platform for the facilitation of correct decisions. Through discussion groups and interviews, five major sports in Australia were examined. All participants in the study had all officiated from the grassroots level to the elite level, where at the latter level, had experience in the use of the relevant technologies adopted by their sport. The findings present that, in the majority of the examined sports, differing degrees of technology is being applied to aid the decision making process. When used the technology does provide the mechanism to facilitate in ensuring the correctness of the decision. The success of the introduction of the decision support technology is dependent on its usability, appropriate application and acceptance by the officials and the participants of the match. Via the diligent use and application of appropriate technologies, they can be used as an effective aid to refereeing. Illegal tactics and play were commonplace prior to the introduction of the use of technology to assist the referee. These areas, however, have been dramatically reduced and to a certain extent eliminated. Subsequently these introduced technologies have been a major contributor to the provision of a fairer platform for competition and led to improved player performance. The findings provide a basis for further studies and possible trials with technologies to assist the referee in providing fair competition and to improve the quality of referees' decision making.
\end{abstract}

Keywords: Decision making, technology, elite sport

\section{Introduction}

The decisions made by a referee or umpire can affect the ultimate outcome of a game. In some situations the direction of the game can be changed by a single decision. Price (2006) and Connelly (2003) noted it is not uncommon for the referee or umpire to be identified as the cause of the failing of a player or team, and to be blamed for influencing the result of a game by either not enforcing the rules or being biased.

Many players, Mascarenhas (2005) reports, however, do not understand the demands placed on referees for split-second decision making and "mastery of the rules". The International Fair Play Committee report that the referee is required to evaluate the important characteristic of an event or situation, and present the appropriate and correct decision in about 1 second. Mascarenhas (2005) highlighted that referees have to respond almost immediately to events in a game that unfold dynamically and which may have many nuances, ambiguities and uncertainties. In general, the elite level referee is required to make rapid decisions while also considering numerous sources of information.

In recent years, there has been an increasing use of technology in a number of areas of sport, although not always to support the referee's decision making. For example, external bodies, such as commentators, coaches and the like, who are in the position of scrutinizing referees' decisions, often have access to modern technologies such as slow-motion replay as well as replay showing differing angles. In some sports this is not available to the referee. In addition, there is considerable investment in the use of technology to support the athletes and the general media, and the development of precise scoring mechanisms as reported by Ford et al (1999).

Such is the current situation, that the elite, high profile sports are now turning to technology to provide tools, mechanisms and processes which can be used by referees as an aid to confirm their

Copyright (C) 2010 René Leveaux. This is an open access article distributed under the Creative Commons Attribution License unported 3.0, which permits unrestricted use, distribution, and reproduction in any medium, provided that original work is properly cited. Author Contact; rene@it.uts.edu.au 
"on field" decisions. This paper presents research into the decision support technologies used in several major sports. The discussion of the findings shows that there is, indeed, a need for such technologies to assist referees, reduce the incidence of controversial decisions and lead to fairer competition.

\section{Research Method}

The study was conducted through discussion groups, a series of interviews and an Internet search. The advantage of doing a qualitative research was that it allowed greater understandings of the interviewees' personal constructs and experiences.
All participants in the study were fully informed and voluntarily consented to their involvement. Participants were also free to withdraw from the research without giving reason or justifying their decision at any time, if they so wished.

All sports that were examined are currently contested in Australia at either the semiprofessional, professional or Olympic level. Any sport which did not use technology in the officiating of the sport was not considered for the research.

\section{Discussion Groups}

Two sets of informal discussions were held. Two discussion groups were held prior to the interviews and web search, and one following. A breakdown of the participants can be found in Table 1.

Table 1: Participants in Discussions and Interviews

\begin{tabular}{|c|c|c|c|c|c|c|}
\hline & Sport & Age & $\mathbf{M} / \mathbf{F}$ & $\begin{array}{c}\text { Years } \\
\text { Referee } \\
\text { Elite }\end{array}$ & $\begin{array}{c}\text { Years } \\
\text { Referee } \\
\text { Total }\end{array}$ & $\begin{array}{c}\text { Years } \\
\text { Involved } \\
\text { in Sport }\end{array}$ \\
\hline \multicolumn{7}{|c|}{ Pre Intreview } \\
\hline $\mathrm{A}$ & $\begin{array}{l}\text { Rugby League } \\
\& \text { Tennis }\end{array}$ & 26 & $\mathrm{M}$ & & & $\begin{array}{l}19 \text { (Rugby League) } \\
11 \text { (Tennis) }\end{array}$ \\
\hline $\mathrm{B}$ & Rugby Union & 22 & M & & 5 & 12 \\
\hline $\mathrm{C}$ & Rugby Union & 26 & $\mathrm{M}$ & 1.5 & 9 & 16 \\
\hline $\mathrm{D}$ & $\begin{array}{c}\text { Cricket } \\
\text { \& Football (Soccer) }\end{array}$ & 42 & $\mathrm{~F}$ & & & $\begin{array}{l}22 \text { (Cricket) } \\
15 \text { (Football / } \\
\text { Soccer) }\end{array}$ \\
\hline $\mathrm{E}$ & Rugby League & 54 & $\mathrm{M}$ & & 18 & 43 \\
\hline \multicolumn{7}{|c|}{ Interview } \\
\hline $\mathrm{F}$ & Rugby Union & 37 & $\mathrm{M}$ & 4 & 17 & 30 \\
\hline $\mathrm{G}$ & Rugby Union & 35 & $\mathrm{M}$ & 6 & 11 & 26 \\
\hline $\mathrm{H}$ & Rugby League & 38 & $\mathrm{M}$ & 8 & 21 & 31 \\
\hline I & Football (Soccer) & 41 & $\mathrm{M}$ & 3 & 15 & 34 \\
\hline $\mathrm{J}$ & Cricket & 41 & $\mathrm{M}$ & 7 & 18 & 31 \\
\hline $\mathrm{K}$ & Tennis & 39 & $\mathrm{~F}$ & 6.5 & 13 & 27 \\
\hline \multicolumn{7}{|c|}{ Post Interview } \\
\hline $\mathrm{L}$ & Taekwondo & 54 & $\mathrm{M}$ & 14 & 26 & 37 \\
\hline $\mathrm{M}$ & Taekwondo & 58 & $\mathrm{M}$ & 8 & 23 & 36 \\
\hline $\mathrm{N}$ & Taekwondo & 32 & $\mathrm{~F}$ & 1.5 & 7 & 15 \\
\hline $\mathrm{O}$ & Taekwondo & 31 & $\mathrm{M}$ & & 7 & 12 \\
\hline
\end{tabular}

To establish a framework for the discussions the following base definitions were employed:

- "Fair play" is defined as contesting a sport where there exists the "observance of the rules, respect for the opponent, and combating violence and unfair behaviour", as defined by the International Olympic Committee (2007). The approach to fair play in sport represents the positive benefits of playing by the rules, using common sense and respecting fellow players, referees, opponents and fans, as noted by the Fédération Internationale de Football Association (2007).

- "Officiating" is defined as involvement in the application of the game rules and regulations 
during the contest - this included on- and offfield referees, umpires and sighting commissioners. The National Association of Sports Officials (2007), in their Sports Officials Code of Ethics, states that the duties of sports officials are to act as impartial judges of sport competitions. In their definitions, this role includes the obligation to perform the expected (officiating) duties with "accuracy, fairness and objectivity through an overriding sense of integrity".

- "Technology", due to its potentially broad definition, was referred to as any electronic device, or collection of devices, currently used to aid or assist the official in the performance of their officiating duties during a match, in their chosen sport. This definition was also extended to include devices that are also used by any third party officiating in the determination or application of the rules and regulations of the sport for a particular match.

- The words "referee" and "umpire" were synonymous, as were "game" and "match". This principle has also been adopted for this paper.

- There are considerable, and varying, definitions of "elite". With respect to this work, elite was defined by Garcia (2001), as competitive sport at the top level of the particular sport and Legrand (2006) notes where the referee has the competencies due to a thorough understanding of the rules and experience to be at the top end of a "very high hierarchy" of sporting officials.

Pre-Interview Discussions

An "interview guide" approach was implemented with the pre-interview discussions, containing issues to be addressed by the participants. As suggested by Patton (1990) this approach allows other related topics to emerge which may be specific to the individual participant. The discussion topics were asked in an open-ended fashion in order to "minimize the imposition of predetermined responses when gathering data", as noted by Patton (1990).

Specific questions related to any issues were not developed, but rather a general discussion mode focusing on the base definitions was employed to allow participants the ability, as discussed in Patton (1990) to "word questions spontaneously" and "to establish a conversation style" with the author, while maintaining focus on the topic. In the course of the initial discussions, new perspectives and related topics emerged, which were also investigated. Followup phone calls were made to two participants where further confirmation of information was required.

\section{Interviews}

A general interview script was developed based on issues derived from comments and points raised in the first set of informal discussions. The same main format of questioning was employed in all interviews. All the participants had officiated at senior levels in their chosen sport, up to and including international competition. McCracken (1988) discusses how interviews can draw on the past as well as the present to extract a deeper understanding of an issue than a simple survey type inquiry. Erlandson (1993) states that the use of semi-structured interviews allows the investigator to ask respondents for facts as well as gathering opinions.

The interviewed subjects were solicited through email or through chain sampling. Patton (1990) states chain sampling "identifies cases of interest from people who know people who know people who are information-rich, that is, good examples for study, good interview subjects". All of the 6 volunteers were chosen for interview on the basis of availability, suitable experience and use of technology in their sport. Erlandson (1993) suggests that this technique of "purposive sampling" is preferred to random or representative sampling because the major concern of the researcher is to maximize discovery of the problem and the heterogeneous patterns that occur within the context of the particular study. Semi-structured interviews were conducted either at the interviewer's office or a location that suited the interviewee. In general the interviews lasted about 40 minutes.

The focus of the questions centered on the views, if any, participants had to the uses of technology and the impact of the use of the technology in relation to fair play and correct decision making in their chosen sport. Any views or opinions in relation to another sport with which the participant was not involved were disregarded. Participants were also asked about their own adaptation to the use of technology, changes to their own officiating practices (if any), and personal viewpoints on technology, in relation to levels of application and introduction, what they enjoyed or did not enjoy with the use of the technology(s) employed in their sport, and what aspects they had or had not appreciated. The interviews were recorded and transcribed for analysis. Follow-up phone calls were made to three respondents where clarification or further investigation was required.

The interview transcripts were analyzed using constant comparison and analytic induction methods, as discussed by Robinson (1951) and Lincoln \& Guba (1985), in order to identify and extract common themes across participants. First, the data for each interviewee were 
reviewed and themes identified, and the themes from each were then compared and contrasted. Common themes were identified and the data reexamined with regard to these data categories.

Internet Search

For a review on the question of decision support technology availability for referees, and o gain a broader perspective of technologies used and accepted across differing sports and Internet search was performed. Google was chosen as the main search engine as Sullivan (2001) reports it is the most comprehensive and Hawkins et al (2001) ranked it about equal to the top in quality. The two search criteria used by the author were "technology and (fair play) and referee" and "technology and (fair play) and umpire". Variations on the search criteria were used but this only revealed a broader and somewhat unrelated range of subject matter. The two searches yielded approximately 466,000 results and 163,000 results respectively. To ensure a most comprehensive study and again to ensure consistency, the top-ranked 100 links were examined. Griffiths and Christensen (2001) and Spink (2005) report that few people search further than the first 10 links.

The results were examined in relation to the key threads that evolved from the interviews, which enabled the author to not only gain a perspective from the arbitrators of the various sports examined in this work, but also gain a broad insight into views from the media, general public and in some circumstances participants of the sport.

\section{Post-Interview Discussion}

The post interview discussion was held with four participants in addition to the author. All participants are actively involved in Taekwondo in Australia, and referee in Taekwondo at either state, national or international competition, or a combination of these.

In the sport of Taekwondo technology is used in the capturing of points sighted by the judges and in the management of game score and time. There is considerable emphasis and pressure by the world governing body for the development and adoption of electronic scoring mechanisms to replace the scoring functions presently performed by the judges.

Using the data drawn from the Internet search and the interviews, potential applications of technology to assist referees' decision making were identified. These were based on eliminating foul play, reducing or eliminating illegal play or tactics, ability to assist in the correct application of the rule(s), ease of use, the provision of a fairer competition and benefits or improvements to player performance. Specific or branded technology was intentionally not identified, but rather the type and applications of technology being used was discussed, and the possible suitabilities of its application to refereeing a Taekwondo match were identified.

The discussion was unstructured and free formatted. A focus was primarily on the introduction of technology to a sport using little or no technology at the elite level. Discussion then centered on the sport of Taekwondo, and the reception of technology by the referee with respect to improving fair play and the ability of the technology to assist referees in their decision making process. The discussion also revealed additional considerations not earlier identified in relation to perceived referee attitudes to the use of technology. Individual responses to the discussion were analyzed, and themes were identified, and where common themes existed the data was re-examined with regard to these data categories.

\section{Findings and Results}

Differing technologies were being used or trialled in all sports examined (see Table 2). Only those technologies used in the actual refereeing process and decision making in a match were considered. The application of technology was occurring at differing player participation levels within the sports, and each sport where technology is used to assist the referee had specific regulations to its application in the game. The use of the technology could only be applied to adjudicate on questions of fact and not on speculation. 
Table 2: Use of Decision Support Technologies in Interviewees' Sports

\begin{tabular}{|c|l|}
\hline Sport & \multicolumn{1}{|c|}{ Technologies Used/Trialled } \\
\hline $\begin{array}{c}\text { Rugby } \\
\text { Union }\end{array}$ & $\begin{array}{l}\text { Microphone and earpieces } \\
\text { Video Referee }\end{array}$ \\
\hline $\begin{array}{c}\text { Rugby } \\
\text { League }\end{array}$ & $\begin{array}{l}\text { Microphone and earpieces } \\
\text { Video Referee }\end{array}$ \\
\hline $\begin{array}{l}\text { Football } \\
\text { (Soccer) }\end{array}$ & $\begin{array}{l}\text { Microchip ball and signal to } \\
\text { referee } \\
\text { Microphone and earpieces } \\
\text { Electronic sensors in goal posts } \\
\text { Video/Electronic Linesman } \\
\text { Tracking systems for off-side } \\
\text { play }\end{array}$ \\
\hline Cricket & $\begin{array}{l}\text { Video/3rd umpire } \\
\text { Sound meter } \\
\text { Hawkeye / Skyscope Tracking } \\
\text { Systems }\end{array}$ \\
\hline Tennis & $\begin{array}{l}\text { Hawkeye Line Calling System } \\
\text { Trinity Net Fault System }\end{array}$ \\
\hline
\end{tabular}

In general, the use of technology in refereeing and match management fell under either all or some of the following three categories:

\section{A. Post Event - Match Analysis}

Video and game analysis software is used by citing commissioners and referees to support decision making in several of the sports. The citing commissioner watches the match for any incidents of foul play that occur which the referee may or may not have seen. Even if the referee has not seen the incident it can be reported by the citing commissioner, requiring the offending player(s) to appear before the sport's judiciary or tribunal. The commissioner's report is supported with video of the incident often showing the incident from different angles.

\section{B. During the Match - Specific Incident Review} Depending on the sport, there exists a mechanism where the referee may used a third party for the assistance in the declaration of a decision. This is typically in situations where a critical decision needs to be made which may affect the outcome of the match. Such instances are, for example, on a line call in tennis, the fall of a wicket in cricket, or the scoring of a try in rugby union or rugby league.

All incidences of this type of review require the match to stop and immediate assessment to take place. The time period involved ranges from roughly $30+$ seconds in tennis using the "Hawkeye" video line calling system, and up to a few minutes in the other sports. Using these systems also allows for transparency in decision making as the incident shown to the spectators in most sports was the same as viewed by the referee and the third party. As one of the interviewees commented:
If I'm uncertain about a call, I won't hesitate to go to the third umpire. I know that everyone watching at the ground and on the TV is going to see it (the situation) and they get it in slow motion and from all angles - so why can't I have that same opportunity to make the right call.

The third party - usually a third or off-field referee, has access to video technology and multiple angles of the incident in which the centre referee seeks assistance. The centre referee stops play and requests that the third referee examine the incident in relation to a specific request based on fact. These requests were all bound by constraints as to the juncture in the play in which they can be made, and only under specific conditions. The requests cannot be made on the basis of seeking another general viewpoint. An interviewee noted:

I can only call to the video ref in certain situations, for example, about a try being scored with regards to matters relating to the grounding of the ball or if I might be undecided if a breach of the rules occurred in that play, such as a forward pass - and when I do use the video ref I have to be explicit in what I ask, e.g., was so and so in an off-side position when receiving the ball or with correct grounding of the ball in a try.

The sports differ in the initiator of the request, as some sports allow the request from the player, e.g., tennis. With the latter, there is some form of control mechanism in place - in tennis the players are permitted to have two "incorrect" challenges per set. 
The "post-interview" discussion group addressed these uses with the game of Taekwondo. Most felt that during a match this would not be appropriate, as a match is very dynamic and to have a facility where a player or referee stops the flow of the match to check on a decision, or potential decision, would be disruptive. It was considered also not appropriate for the player to have this facility as it could be used tactically by a player.

However, this group did feel that the application of the immediate video analysis/feedback could be used in a Sudden Death match. Especially in contentious situations, such as when two players kick a scoring kick at almost at the same time, a process involving immediate video feedback could be utilized to confirm or even ensure the correct winner. However, the method and situations of use would have to be clearly defined. This was probably best summated by one participant's comment:

It's important not to interrupt the match with endless use of "going to the video" for decisions - that would make the match boring. Anyhow, its up to the referee to make decisions and keep the game flowing - that's part of the job. But video ref, or something like that, could work really well in an important match, like a gold medal match, which goes to sudden death when its almost impossible to see who actually scored first. At least that way everybody can be certain the right person is the winner.

\section{During the Match-Advice to the Centre}

Referee

Considerable research is being conducted in some sports to develop or enhance technologies that will act in an advisory capacity during the match, without the need to stop the match, but rather while maintaining the normal tempo of the game. Football (soccer) has been closely examining and testing the micro-chipping of the ball, to signal a scored goal. In other sports, such as rugby, the side-line touch judges contact the center referee via microphones and earpieces, without stopping play. This includes volunteering information to the referee on offside, foul or illegal play, line calls, etc, as it occurs. If appropriate this is then assessed by the referee to determine if any action is warranted or not, without interrupting the continuity of the match:

Since the touch judges have been wired to the ref, a huge amount of foul play, especially in back play, has been stamped out and there is now a greater deterrent for illegal play; because the players know if they cheat, they are not going to get away with it. And it interesting enough - they're now just getting on with playing the game.
In general, when players knew that the referee had additional resources to assist in their judgments directly via other match officials, there was less tendency for players to commit intentional fouls. And when unintentional fouls were being addressed, there was some greater degree of acceptance of the referee's subsequent action by both the players and coaching staff, as this statement demonstrates:

... you really notice the difference in games when I'm reffing [sic] and wired to the touch judges, compared to when I am not, as the penalty count for the intentional penalties virtually always drops when I've got the touch judges helping out ... and I also don't seem to get as many complaints from the coaches and players.

The "post interview" group identified that, in the sport of Taekwondo, the main areas that coaches and players often complain about is holding, falling and crossing the boundary line. It was felt that there could be a role for technology in these areas, however it was stressed it should be as an aid to the referee in decision making. The referee should still be the administrator of any warranted penalty, as one participant explained:

In some games you virtually know there is some holding going on and one of the players and his coach is complaining - but it's on the blind side and you can't see it, and as soon as you're in a position to actually see it, the player lets go. And the really frustrating part is that the corner judge can probably see it as clear as day. It would be great if they (corner judge) could say something like Chung [Blue] is holding or pulling on Hong's [Red] hogue [chest protector]. I bet if the players knew there were extra sets of eyes on them, and they could be caught, they'd stop doing it.

\section{Discussion}

Those interviewed and the discussions groups felt there was a definite place for technology in refereeing to support their decisions. It was evident that it should only be used as an aid in the decision making process and that ultimately the referee should be the final arbitrator. The referee should also not become dependent on technology. All felt that sport needed to be officiated by a referee(s) - not by technology due to the myriad of situations that occur in competition which ultimately could not be interpreted purely by technology.

The participants currently using some form of technology with refereeing, identified that there is a learning curve and adaptation process to be met. The success of the technology is dependent on all the officials understanding the role of the 
technology being used, the guidelines or regulations for its use being appropriately structured, and the group officiating in a match using the technology constructively to support the decision making process of the referee. This was identified by the following comment:

When you first start reffing [sic] with a microphone, it take a bit of getting used to hearing somebody's voice talking in your ear every now and then, but once you're used to it, and the touch judges are helping you with your calls, it works really well. I now use the mics [microphones] whenever I can - even in club games. I like it, the players like it, it helps me eliminating illegal play and in general helps to call a fairer and more enjoyable game.

\section{Conclusion}

This work shows that differing technologies have successfully been implemented in various sports, and this has greatly improved the playing environment and assisted the referee/umpire to promote fair play. In some of the contact sports illegal play and foul play have been greatly eradicated via the use of technology. This promotes a more attractive sport for both the spectators and the players due to the contest being determined without illegal play or tactics, but rather on the athletic ability and performance of the participants.

This work also shows that there is a certain acceptance that must be achieved by the referee/umpire and the players of the sport. This can be achieved by the technology being used as an aid in the management of the game, rather than a tool to administer the rules and regulations during the game. As with the ability of the athlete to vary and adapt the way in which he/she plays the game, so too should the management of the game remain ultimately a human function. There will always be the need to interpret and assess an infraction based on the situation surrounding it, and this could not be done purely using technology. If rule interpretation were to be administered using technology without the application of the referee's knowledge, then the overall flow of the competition would more than likely cease, and even the most minor and possibly insignificant and unintentional infractions would be penalized. Appropriate technology should be an aid to the referee to further enhance better decision making in order to improve the quality of the match and provide fairer competition.

\section{Further Research}

These results are drawn from only a limited sector of today's professional and elite sports, and only from those to which the author had immediate access. The findings of this study should be considered in that light. The study does lay the foundations for further, more detailed research to be constructed to examine the potentiality of technology and its impacts on a range of sports with respect to fair play, usability and acceptance of technology by the referee, player, coach and spectator. A further and more detailed study would provide a more solidified confirmation of the findings of this study. The results of such studies would enable sports administrators to be able to introduce technologies with a more complete understanding, and to be able to tailor their introduction to focus on promoting better decision making, a fairer competition platform and subsequently improved player performance.

\section{Acknowledgements}

The author would like to thank the participants from the various sporting groups who volunteered their time for this study.

\section{References}

CIFP - International Fair Play Committee Introduction, From: http://www.fairplayinternational.org/introducti on.php

Connelly, J. (2003), "Doing the Best They Can", The World and I. Washington: Oct 2003: 1810,162 .

Erlandson, D. A. (1993), Doing a Naturalistic Inquiry: A Guide to Methods, Newbury Park, CA.

FIFA (2007) FIFA and Fair Play, From: www.fifa.com/en/fairplay/index.htm

Ford, G. G., Gallagher, S. H., Lacy, B. A., Birdwell, A. M., Bridwell, A. M. and Goodwin, F. (1999), "Repositioning the Home Plate Umpire to Provide Enhanced Perceptual Cues and More Accurate Ball-Strike Judgments", Journal of Sports Behavior; 22(1): 28-44.

Garcia, R. (2001), "Elite sports in the net. Is there a virtual community for elite sports in the Internet?", Proc of CAR 2001: $2^{\text {nd }}$ International Forum on Elite Sports, 81-82

Griffiths, K. M. and Christensen, H. (2000), "Quality of Web Based Information on Treatment of Depression: Cross Sectional Survey", British Medical Journal, 321 (7275) Dec: 1511-1515.

Hawking, D., Craswell, N., Bailey, P. and Griffiths, K. (2000), Measuring search engine quality. Information Retrieval, 2000. In Press. Available from

URL: 
http://citeseer.nj.nec.com/hawking01measuring .html

IOC (2007), The International Committee for Fair Play,

From:

http://www.olympic.org/uk/organisation/actio ns/index_uk.asp

Jones, M. V., Paull, G. C. and Erskine, J. (2002), "The Impact of a Team's Aggressive Reputation on the Decisions of Association Football Referees", Journal of Sports Sciences, 20, 9911000.

Legrand, C. (2006), "Referees: From Amateurism to Professionalism in France", Proc. of INSEP 2006: $4^{\text {th }}$ International Sports Sciences, 41-42

Lincoln, Y. and Guba, E. (1985), Naturalistic Inquiry. Newbury Park, CA: Sage.

Mascarenhas, D. R. (2005), "The Accuracy, Agreement and Coherence of Decision-Making in Rugby Union Officials", Journal of Sport Behaviour, 28, 254.

McCraken, G. (1988), The Long Interview, Newbury Park, CA.
National Association of Sports Officials (NASO) (2007), Sports Officials Code of Ethics, From: http://www.naso.org/ben efits/ethics.htm

Patton, M. (1990), Qualitative Evaluation and Research Methods (2nd ed.). Thousand Oaks, CA: Sage Publications.

Price , K. (2006), "Officials Encouraged to Blow it”, Sporting News, May 5: 230, 18.

Robinson, W. S. (1951), "The Logical Structure of Analytical Induction", American Sociological Review, 16, 812-818.

Spink, A. (2005), "Web Search Trends Project: 1997-2005", paper presented at The Faculty of Information Technology Research Seminar, University of Technology, Sydney 25 May.

Sullivan, D. (2001), The Search Engine Report [Online] from: http://www.searchenginewatch.com/reports/si zes.html 